\title{
Pitch memory for short tones ${ }^{1}$
}

\author{
LOIS L. ELLIOTT ${ }^{2}$ \\ CENTRAL INSTITUTE FOR THE DEAF
}

Ten listeners judged a 300-msec tone as higher or lower in pitch than another 300 -msec tone that occurred 8 sec earlier. The intervening time either was unfilled or contained a 400-msec interpolated tone. This interpolated tone occurred either just after the first tone or just before the final one, and was of a frequency either inside or outside the critical band of the target frequency. Performance for the silent-interval condition was about as good as has been reported for pitch discrimination with no delay when the target was $250 \mathrm{~Hz}$ but was slightly poorer for the target at $1,550 \mathrm{~Hz}$. Presence of the interpolated tone decreased the slope of the psychometric function and produced constant errors for nine $S \mathrm{~s}$. These effects were more pronounced when the interpolated tone occurred $50 \mathrm{msec}$ after the target than when it preceded the comparison tone by 50 msec. Both brevity of the tanget tone and occurrence soon thereafter of an interpolated tone are required to produce constant errors of pitch memory.

This experiment on pitch memory, which employs a modification of traditional pitch-discrimination procedures (e.g., Postman, 1946), is also related to two other fields of investigation. The first concerns those auditory masking experiments that suggest that frequency representation of a tonal signal, at one or more levels in the auditory system, is initially widespread and requires time to narrow into a steady-state configuration. This process has been termed "development of auditory frequency contours [Elliott, 1967]." The memory for the pitch corresponding to such contours may be modified or obscured if another short tone, of different frequency, intrudes before the frequency contour has become stable.

A second body of experiments, most often employing verbal rather than tonal stimuli, are those concerned with "short-term memory." Among both oneand two-stage theories of memory, there is general agreement that the initial phase of echoic memory (Neisser, 1967) endures for about 1 to $4 \mathrm{sec}$ and that when material is in this state of acoustic storage (termed "pre-categorical acoustic storage" by Crowder \& Morton, 1969) it may decay or be overwitten by other material.
Extrapolations from the studies concerned with development of auditory frequency contours and with verbal memory ${ }^{3}$ suggest that pitch memory should be selectively degraded for particular stimulus conditions.

In a previous study (Elliott, 1968), which employed a method of adjustment task, small individual differences in pitch discrimination became accentuated when memory requirements were added to the (pitch-discrimination) task. These differences persisted and were not eliminated by practice. In the present situation, there was also interest in determining whether similar individual differences would be observed with a different psychophysical procedure.

Selection of those stimulus conditions that would most likely demonstrate degradation of certain aspects of pitch memory included the following considerations: Duration of the tonal signal should be long enough for it to just "narrow" frequency contours (e.g., about $250.300 \mathrm{msec})$, and for pitch discrimination not to be degraded in the absence of an interpolated tone (Tumbul, 1944). Also, the duration of the target should be sufficiently brief that long-term memory processes (i.e., long-term storage, rehearsal) are not initiated while the target continues to sound. The time interval between occurrence of the target and comparison tones should be longer than the duration of echoic storage and yet not so long. that considerable decay would be expected to occur; an interval of 8 to $10 \mathrm{sec}$ would appear to meet this requirement. The added, or "interpolated," tone should occur very soon after the target signal if it is to interact with the frequency contour for the target. (If the role of the interpolated tone were not that of "interaction" and instead were a general diverting of S's attention, then occurrence of the interpolated tone just prior to the comparison tone might be expected to be more, or at least equally, disturbing.) The interpolated tone should neither occur so soon after the target tone nor differ sufficiently from it in intensity that masking patterns evolve between the two tones.

One might expect an interpolated tone located within the critical band of the target tone to be more disrupting than one located outside the critical band if the concept of the critical band is relevant to this situation, which involves suprathreshold levels, longer time durations, sequential presentation, and memory processes. However, since the ensemble of experimental parameters is considerably different from most situations in which the concept of the critical band has proven pertinent, there was less reason for anticipating results here to be related to critical band concepts.

A flattening of the psychometric function would be the expected experimental result if the effect of the interpolated tone were primarily to accelerate decay of the frequency contour of the target, thus producing a general loss in accuracy of pitch memory (i.e., increase in the variance of the judgments). However, if there is a specific interaction between frequency contours of the target and of the interpolated tone such that the peak of the target contour shifts in the direction of the frequency of the interpolated tone, then one might expect constant exrors of pitch memory (i.e., evidenced by a shift of the psychometric function).

The major purpose of this experiment, then, was to test two hypotheses: (1) A tone interpolated between a brief target tone and an equally brief comparison tone will produce changes in pitch discrimination memory that will be manifest by a flattening of the psychometric function or by a constant error in pitch memory (or both); and (2) the magnitude of this degrading effect will be greater when the interpolated tone occurs very soon after the target tone than when it occurs immediately prior to the comparison tone. In addition to testing the main hypotheses, this experiment also was designed to provide empirical information about the role of the critical band in this situation and about individual differences in pitch memory.

\section{Stimuli}

\section{METHOD}

Previous, unpublished work has suggested that pitch memory might be better in a range of frequencies encompassed by the voice fundamental. It was appropriate, therefore, to sample a low frequency and also one above $1,000 \mathrm{~Hz}$, where critical-band measurements are quite firm. In a pilot study, a single (compromise) frequency was $600 \mathrm{~Hz}$, while 
Table 1

Experimental Conditions

\begin{tabular}{|c|c|c|c|}
\hline Frequencies & Pilot Study & Main & Experiment \\
\hline Nominal Target & $600 \mathrm{~Hz}$ & $250 \mathrm{~Hz}$ & $1,550 \mathrm{~Hz}$ \\
\hline $\begin{array}{l}\text { Jitter Associated with } \\
\text { Target Frequency }\end{array}$ & $0, \pm 4, \pm 8, \pm 16 \mathrm{~Hz}$ & $0, \pm 6, \pm 12 \mathrm{~Hz}$ & $0, \pm 8, \pm 16 \mathrm{~Hz}$ \\
\hline $\begin{array}{l}\text { Comparison Tone, } \\
T+\Delta f \text {, Where } \Delta f=\end{array}$ & $\begin{array}{l}0, \pm 2, \pm 4, \pm 8 \\
\pm 12, \pm 16 \mathrm{~Hz}\end{array}$ & $\begin{array}{l}0, \pm 3, \pm 6, \pm 9 \\
\pm 12, \pm 15, \pm 18 \mathrm{~Hz}\end{array}$ & $\begin{array}{l}0, \pm 4, \pm 8, \pm 12, \\
\pm 16, \pm 20, \pm 24, \pm 28 \mathrm{~Hz}\end{array}$ \\
\hline $\begin{array}{l}\text { Interpolated Tone } \\
\text { Inside-Band } \\
\text { Ou tside-Band }\end{array}$ & $\begin{array}{l}T \pm 16, T \pm 24 \mathrm{~Hz} \\
T \pm 80 \mathrm{~Hz}, T \pm 100 \mathrm{~Hz}\end{array}$ & $\begin{array}{l}T \pm 20 \mathrm{~Hz} \\
120 \mathrm{~Hz}, 410 \mathrm{~Hz}\end{array}$ & $\begin{array}{l}\mathrm{T} \pm 50 \mathrm{~Hz} \\
1,150 \mathrm{~Hz}, 2,000 \mathrm{~Hz}\end{array}$ \\
\hline
\end{tabular}

in the main experiment both 250 and $1,550 \mathrm{~Hz}$ were used.

Other features of the pilot study and the main experiment are outlined in Table 1 and Fig. 1. Duration of the target and comparison tones was $300 \mathrm{msec}$ and rise/fall times were $20 \mathrm{msec}$. The time between each pair of target and comparison tones was $10 \mathrm{sec}$ in the pilot study and $8 \mathrm{sec}$ in the main experiment. (Time between target and comparison tones was decreased in the main experiment in order to decrease total listening time.) In Condition 2 this time interval was silent but in Conditions 1 and 3 it contained a $400-\mathrm{msec}$ interpolated tone having the same $20-\mathrm{msec}$ rise/fall time. In Condition 1 the interpolated tone started $50 \mathrm{msec}$ after the target tone ended, while in Condition 3 the interpolated tone ended $50 \mathrm{msec}$ before the onset of the comparison tone. Durations and rise times were measured at points where the power was half that in the steady-state portion. There was a 3-sec intertrial interval during which the listener responded, and between every 10 trials there was an additional $5-\mathrm{sec}$ interval during which the trial number was announced. Roving standard procedures (Harris, 1952a) were used; that is, a frequency "jitter" (outlined in Table 1) was imposed so that each nominal target actually assumed five different values-its nominal value and the four jittered values (in the pilot study, six jittered values were used in addition to the nominal target frequency). For example, the $250-\mathrm{Hz}$ target was $256 \mathrm{~Hz}$ (jitter $=+6 \mathrm{~Hz}$ ) on some trials and $238 \mathrm{~Hz}$ (jitter $=-12 \mathrm{~Hz}$ ) on some other trials. This frequency variation for the nominal targets prevented $S$ from developing an absolute pitch standard and required him to attend to the target for every trial. Jitter values were not differentiated in analysis of the results.

Frequency of the interpolated stimuli is shown in Table 1. Note that in the main experiment, the inside-critical-band interpolated tone moved with the jitter of the target frequency, while the outside-critical-band interpolated tone was one of two frequencies.

CONOITION 1

CONDITION 2

CONDITION 3 majority of listeners, but for three it was probably an undesirable feature.

(Most of the following discussion refers to the main experiment specifically; unless mentioned otherwise, procedures and results were approximately the same for the earlier pilot study.)

Each stimulus tape contained trials with only one of the three temporal conditions. All other features including the two target frequencies were randomized within the tapes. Three different versions of Condition 2, with 90 trials each, were prepared; each of these contained five replications of each target- $\Delta \mathrm{f}$ combination. Four tapes of 95 and 90 trials each, respectively, were required to contain five randomized replications of all targets (with associated jitter), interpolated tones, and comparison tones for Conditions 1 and 3 . Attenuation was controlled so that the completed materials, when played through an Ampex AA620 speaker in a quiet room were received at about $40-\mathrm{dB}$ sensation level at all frequencies from 120 to $2,000 \mathrm{~Hz}$.

Stimuli were generated with an ensemble of Tektronix timing gear, three oscillators, three frequency counters, three electronic switches, and associated attenuators, mixers, etc. A one-trial sequence of two (for Condition 2) or three tones was produced in the following manner: Attenuators were set, frequencies were set and checked with the three counters, the Tandberg $62 \mathrm{X}$ tape recorder was started, the sequence of tones was recorded, the tape recorder was stopped, and the following trial was set up.

Subjects

Ss were 10 young adults with normal

\begin{tabular}{|c|c|c|}
\hline TARGET & \begin{tabular}{|} 
INTERPOLATEO \\
TONE
\end{tabular} & COMPARISON \\
\hline MSEC & MSEC & \\
\hline
\end{tabular}
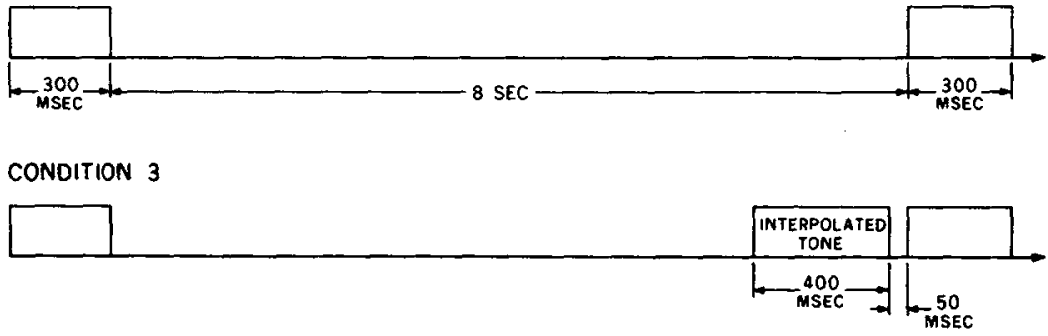

Fig. 1. Diagram of the three types of stimulus trials. For Condition 1 , the interpolated tone occurred 50 msec after the target while in Condition 3 it occurred 50 msec prior to the comparison tone. Condition 2 contained no interpolated tone. Each listening tape contained trials for only one experimental condition; all other features of the experiment, including the two target frequencies (main experiment), were randomized within tapes. 
Table 2

Frequency Discrimination with No Interpolated Tone

Target Frequency $(\mathrm{Hz})$

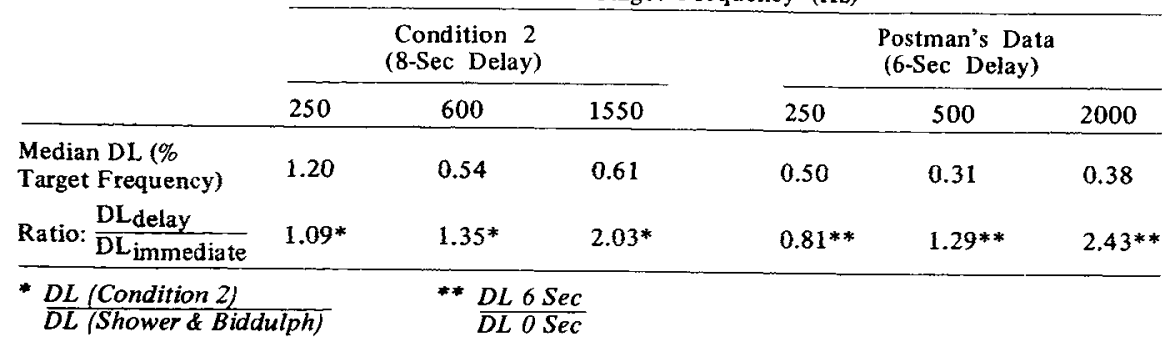

hearing who agreed to participate in the 2-h listening session every day for 3 weeks. Age range was 17 to 21 years; four listeners were fernale; all had normal hearing; and all were compensated for their services. (Four similar listeners had previously participated in eight sessions of the pilot study; one of these later participated in the main experiment.)

\section{Procedure}

At a typical session, four different tapes were presented to a group of four or five listeners; conditions were randomized by tapes within sessions. Each listener judged every tape at least once before experimental data were collected. Listening continued until each stimulus combination had been replicated 25 times for each listener.

Answer sheets contained places for judging the comparison stimulus of each item as "higher" or "lower" than the target. Listeners were not given immediate feedback but, on the following day, were told how many items had been correct on each of the preceding day's tapes and whether or not their judgments indicated excessive response bias. Scoring by stimulus combination did not keep pace with data collection; if it had, the behavior observed among three listeners would have been noted, and announcement of number of trials "correct" (i.e., corresponding to $\Delta f)$ on the preceding day would have been eliminated (point to be discussed later).

Listeners' enjoyment of this task appeared to be directly related to their success. Some learning occurred during practice sessions but none appeared during the experiment proper.

Answer sheets were scored for number of responses judged "higher" for each target-frequency/ $\Delta$ f-interpolated tone combination. Percentages for each listener at each stimulus combination were normalized and fitted with a straight line by least-squares procedures; also obtained was the (fitted) point of subjective equality (PSE). Position of the PSE determines whether or not constant errors for pitch memory occur; if there is no constant error, PSE should not differ from $\Delta \mathrm{f}=0 \mathrm{~Hz}$. For Condition 2, a difference limen (DL) was calculated as half the $\Delta f$ distance between projections onto the abscissa from the regression points of $25 \%$ and $75 \%$ "higher" judgments.

In some of the following discussion, $\Delta f$ has been converted to percent of target frequency. However, in the graphs, $\Delta f$ is plotted in hertz on the abscissa and percent "higher" (not normalized) is displayed on the ordinate.

\section{RESULTS}

Major findings may be grouped into three areas: accuracy of pitch memory when no interpolated tone is present, effect of the interpolated tone on the psychometric function, and constant errors of pitch memory. Individual differences, which are not pronounced for Condition 2 become accentuated when the in terpolated tone of Conditions 1 and 3 is added.

\section{Pitch Memory with No Interpolated Tone}

Accuracy of pitch discrimination in Condition 2 is not severely degraded by the brief duration of the stimuli, the two target regions, the roving standard procedure, or the temporal delay of 8 or $10 \mathrm{sec}$ between target and comparison tones (Table 2) neither do constant errors of pitch memory occur for Condition 2 with the unfilled silent interval. Addition of two target markedly change the DL as compared to the pilot study, which had only one target region. At $250 \mathrm{~Hz}$, the median DL of $1.2 \%$ of target frequency is 1.09 times the size of the DL observed by Shower and Biddulph (1931). The median DL of $0.54 \%$ at the $600-\mathrm{Hz}$ target frequency, which was obtained in the pilot study, is 1.35 times the size of the Shower and Biddulph value and the median of $0.61 \%$ at $1,550 \mathrm{~Hz}$ (main experiment) is 2.03 times that observed in the classic study. One would expect the size of the observed DL, in percentage units, to decrease consistently as target frequency increases (within this range of target frequencies). That it does not decrease at the same rate as occurred in frequencies in the main experiment did not the Shower and Biddulph study suggests that memory for higher frequencies is more degraded by the intervening time interval. ${ }^{4}$ More accurate "memory" at low frequencies may be related to the possibility that lower-frequency targets could more easily be coded, stored, and rehearsed by voice mechanisms.

These results are compared with Postman's data (1946) in an experiment employing target and comparison tones of longer duration (1 sec). Although Postman used a paired-comparison procedure, he did not employ a "roving standard [Harris, 1952a]" and apparently a block of trials at one target frequency was completed before a different target frequency was introduced. Under these circumstances, his four experienced listeners obtained DLs, at the 6-sec time delay, that were half the magnitude of DLs observed in Condition 2 of this experiment (Table 2). When the ratio of DLs at the 6-sec time delay is compared to that at 0 -sec delay, however, frequency discrimination performance at $2,000 \mathrm{~Hz}$ is more degraded by the delay than it is at $250 \mathrm{~Hz}$ and the order of magnitude of the ratios is similar to that observed when results of the present study are compared to data from Shower and Biddulph (Table 2).

\section{Slope of the Psychometric Function}

Presence of the interpolated tone in Conditions 1 and 3 generally flattened the psychometric function (Table 3). The slope for Condition 2 (no interpolated tone) was larger than for any of the other eight functions (four each, for Conditions 1 and 3) for 8 out of 10 listeners when the target was $250 \mathrm{~Hz}(p<.001)$ and for 9 of 10 listeners when the target was $1,550 \mathrm{~Hz}$ $(\mathrm{p}<.001)$. Furthermore, the average of the four slopes of the psychometric functions was smaller (i.e., the function was flatter) for Condition 1 than for Condition 3; this was true at both $250 \mathrm{~Hz}$ and $1,550 \mathrm{~Hz}$ for all 10 listeners $(\mathrm{p}<.001$ for each of the tests). Also, in the pilot study at $600 \mathrm{~Hz}$, where data were averaged for the 4 listeners, magnitudes of slopes of the psychometric functions ranked: Condition $2>$ Condition $3>$ Condition 1 .

\section{Constant Errors}

Presence of the interpolated tone also introduced constant errors for nine of the listeners. Since this did not occur for Condition 2 and since the direction of the constant errors was dependent upon the sign of the frequency difference between the interpolated tone and the target (J $-T)$, one concludes that this effect is attributable to the interpolated tone and not to the time delay. 
Table 3

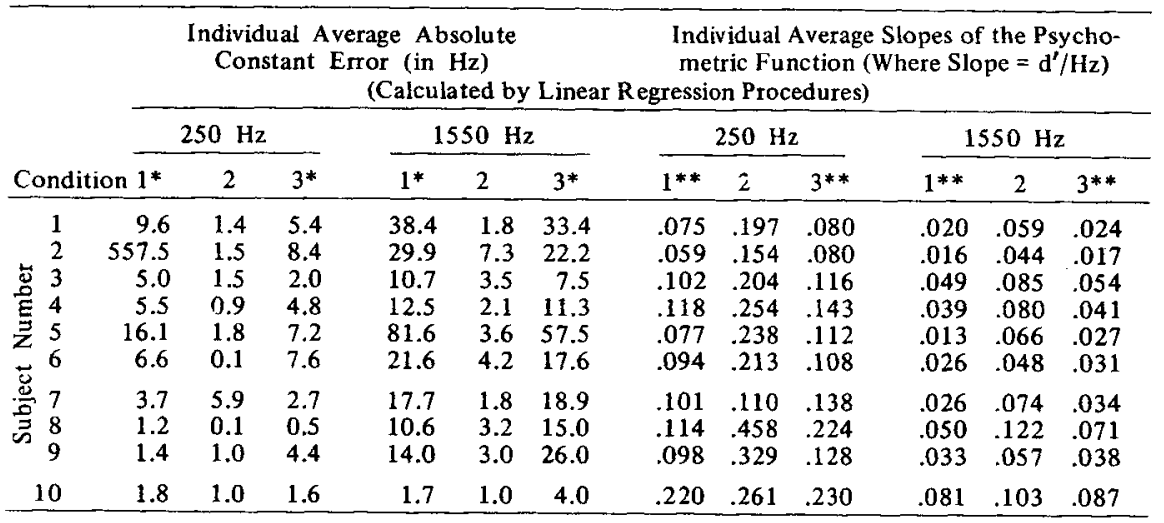

* Absolute average of four constant errors-one for each interpolated tone condition.

* Average of four slopes-one for each interpolated tone condition.

\section{Individual Differences}

Listeners could be divided into three groups on the basis of their responses to Conditions 1 and 3. Six listeners (including the one who had participated in the pilot experiment) produced results of the same type that were observed in the pilot experiment and were designated Group 1. Several in this group were musicians, and several had received limited listening experience in other experiments. Their results may be characterized in the following ways. For Condition 1, when the intervening tone was higher in frequency than the target $(I-T>0)$, the PSE also was higher than the target. When I - T $<0$, the PSE was lower. At $250 \mathrm{~Hz}$ this occurred without exception for all six Ss of Group 1; at $1,550 \mathrm{~Hz}$ it occurred without exception for five Ss (and for the sixth $S$, only one of the five scores was misplaced); the probability of this occurring by chance is less than .001 at each target frequency. Also, for Group 1, the sum of absolute sizes of the constant errors was larger for Condition 1 than for Condition 3; this occurred for five of the six listeners when the target frequency was $250 \mathrm{~Hz}(\mathrm{p}=.109)$ and for all six listeners when the target was $1,550 \mathrm{~Hz}$. (This last statement concerning the relative size-not direction-of constant errors was true for 8 of the 10 listeners at $250 \mathrm{~Hz}$ and for 7 of the 10 listeners at $1,550 \mathrm{~Hz}$.)

Typical of performance of Group 1 are results of JG, which are shown in Figs. 2 and 3. JG was a 21-year-old male college

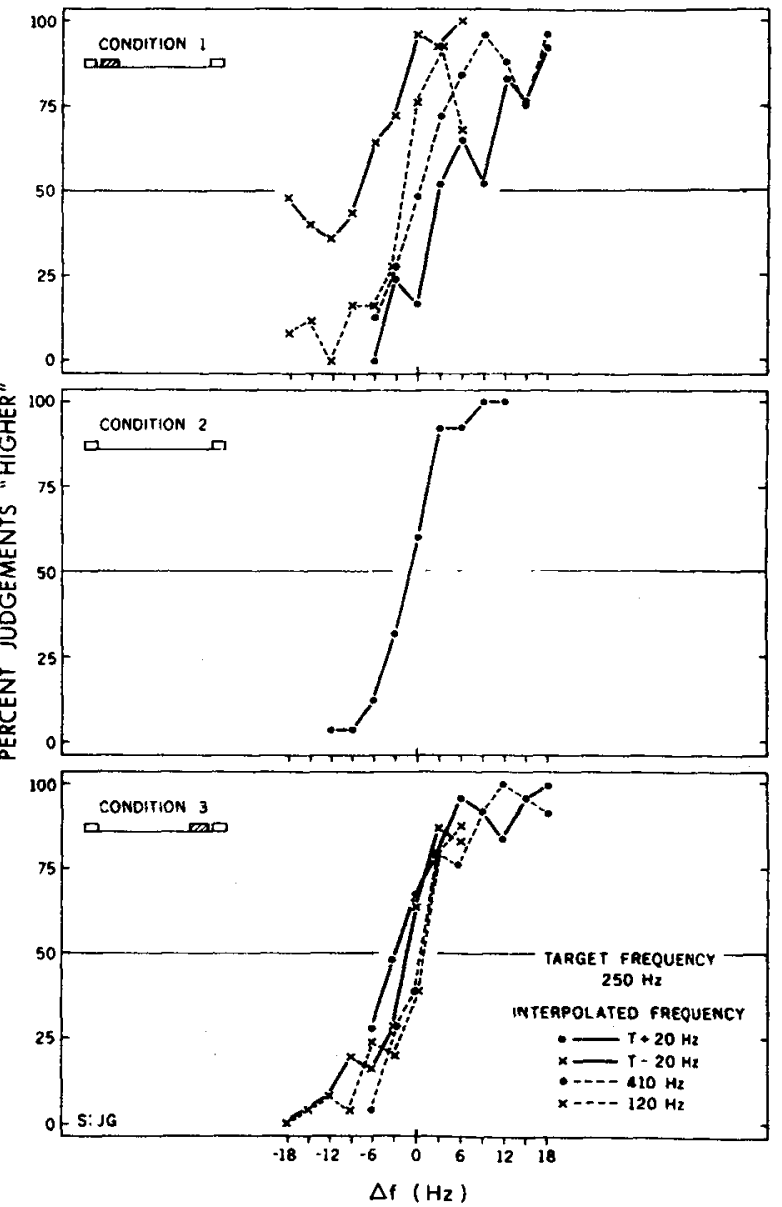

Fig. 2. Results at the $250-\mathrm{Hz}$ target frequency for a listener (JG) classified in Group 1. Each data point in this and following figures is based on 25 judgments obtained over a 3-week period.

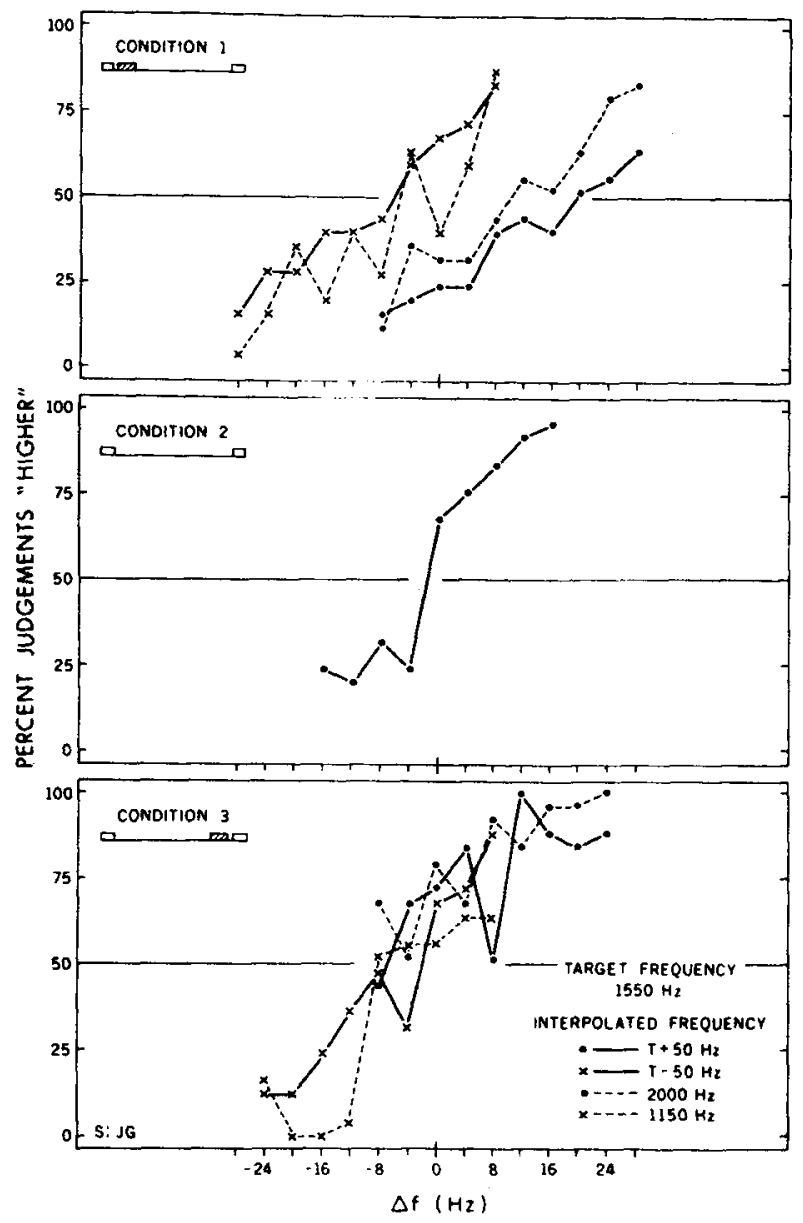

Fig. 3. Results at the $1550-\mathrm{Hz}$ target frequency for JG. 

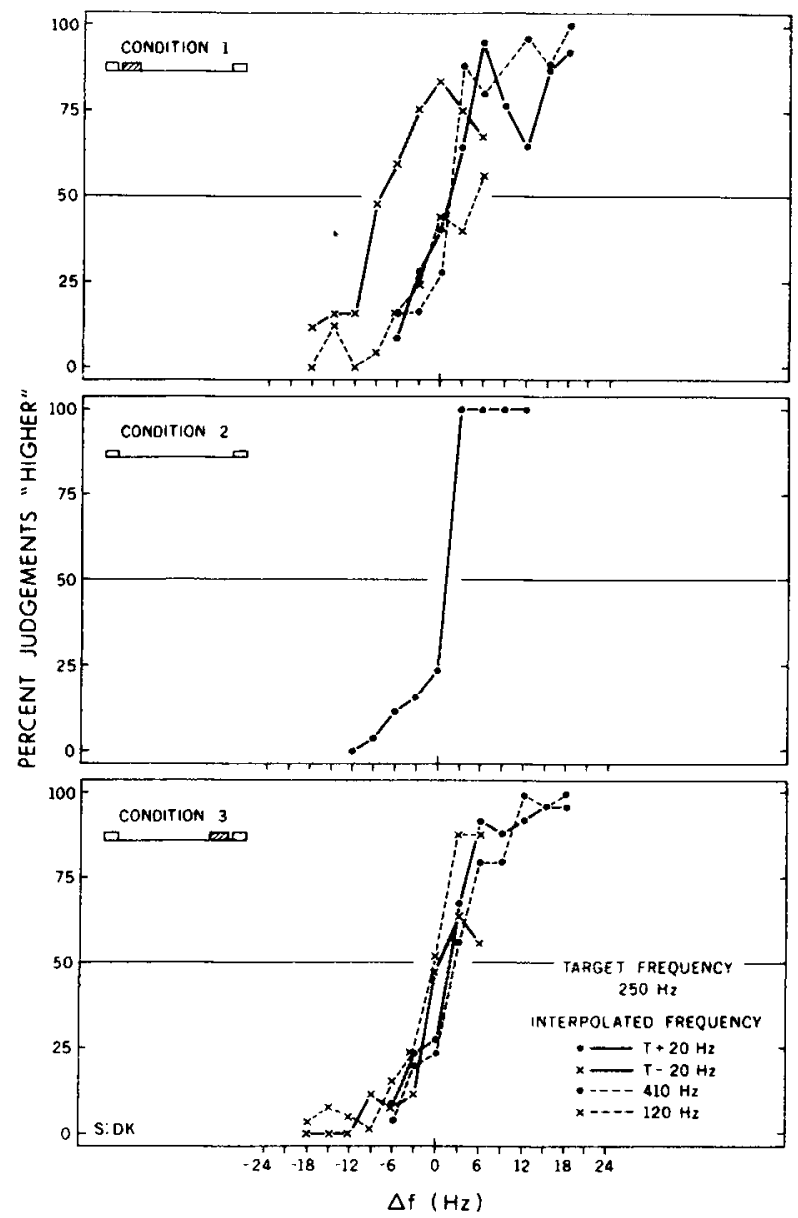

Fig. 4. Results at the $250-\mathrm{Hz}$ target frequency for a listener (DK) classified in Group 2.

student who played the guitar, sang, had received some musical training, but had never before participated in a listening experiment. His DL for Condition 2 is almost as small as for the most experienced listener. Effect of the interpolated tone is most apparent for Condition 1 (upper panel of both figures). For the target at $250 \mathrm{~Hz}$ (Fig. 2) when I-T>0 and with in the critical band (indicated by circles connected by continuous lines) the PSE is shifted up to $255 \mathrm{~Hz}$; when $\mathrm{I}-\mathrm{T}<0$ and inside-band (indicated by crosses and continuous line in the figures) the PSE is shifted down to $238 \mathrm{~Hz}$ (calculated by regression line). Outside-band interpolated tones have a much smaller effect. For the target at $1,550 \mathrm{~Hz}$, effect of the inside-band interpolated tone in Condition 1 (top panel of Fig. 3) is again stronger than for the outside-band interpolated tone. For Condition 3 much smaller shifts in the PSE occur at both target frequencies. Particularly at $1,550 \mathrm{~Hz}$ for Condition 3 , the curves intertwine with only a slightly smaller slope than that
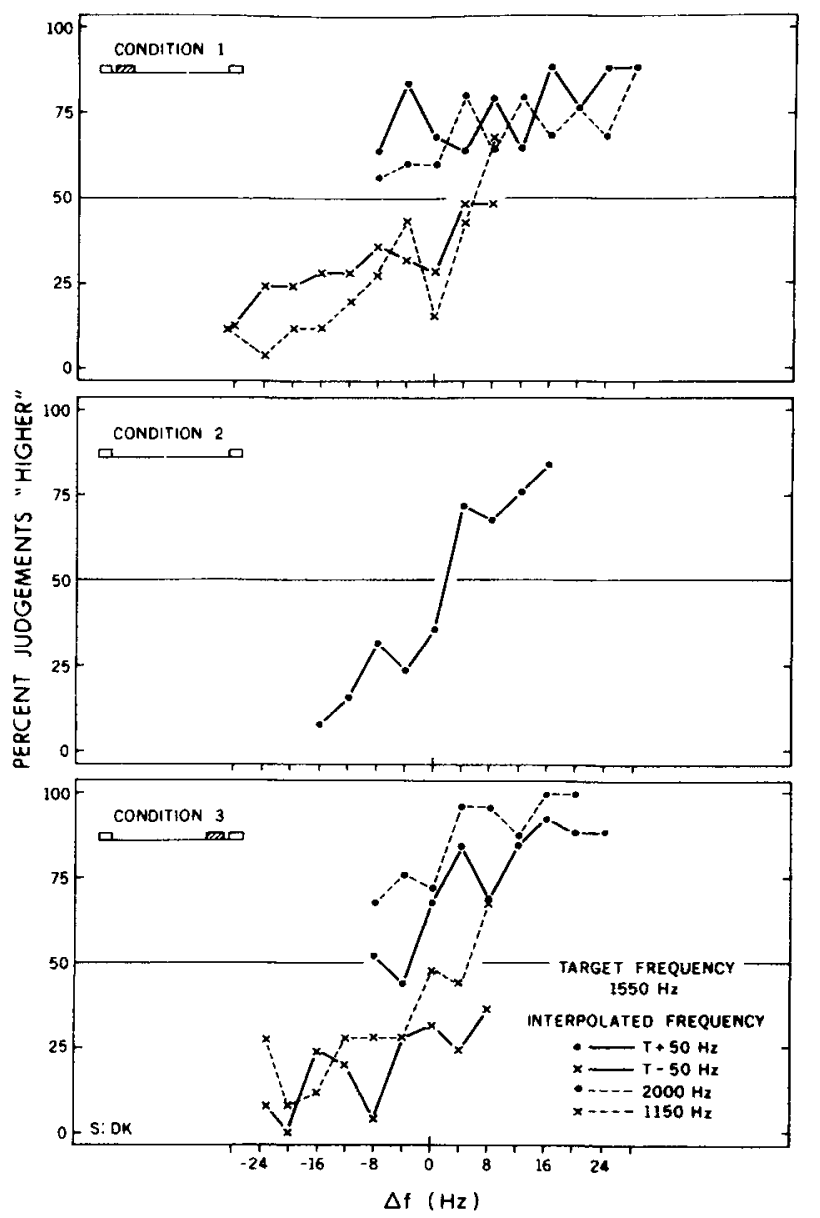

Fig. 5. Results for DK at the 1550-Hz target frequency.

observed for Condition 2 at the same frequency.

Although JG was consistent in displaying greater shifts in PSE for inside-band interpolated tones, that feature was not consistent for all Ss of Group 1 . Two Ss consistently had a larger PSE for outside-band interpolated tones. The other three Ss of Group 1 did not have a completely consistent pattern of shifts for the inside- vs outside-band criterion, although they did display consistent patterns of shifts for interpolated tones higher and lower than the target frequency.

Three Ss were clustered as Group 2 on the basis of their performance on Condition 1 trials. Figures 4 and 5 display results for DK, a typical member of Group 2. For Condition 1 at $1,550 \mathrm{~Hz}$, when $\mathrm{I}-\mathrm{T}>0, \mathrm{DK}^{2}$ 's results show a PSE that is lower in frequency than the target-a shift opposite to that of JG. Similarly, when $\mathrm{I}-\mathrm{T}<0$, the PSE for DK is higher in frequency than the target. Whether the interpolated tone is inside or outside the critical band has no particular effect for DK or for the other two members of Group 2 who exhibited this same type of response.

Two listeners of Group 2 had received considerable listening experience in detection experiments where a bonus salary had been paid for high levels of correct detection and the third member of this group had participated in other types of listening situations. Questioning after the experiment had ended revealed that listeners had not been aware of the assymmetry of $\Delta \mathrm{fs}$ in the test construction. This assymmetry made the response strategies of Group 2 highly effective in maximizing number of trials correct per session. One listener (DK) acknowledged that he had been aware of conscious intellectualization in attempting to overcome effects of the interpolated tone. The process as he described it was: "The interpolated tone was higher in pitch than the target, which would make the comparison tone seem to sound lower in pitch. Therefore, although the comparison tone sounded lower, I should judge it 
higher because it probably was." Following this strategy, DK, like the other two listeners of Group 2, succeeded in achieving a higher number of correct trials than was true of listeners in Group 1. (DK's strategy did not preserve the slope of the psychometric function, which, for Condition 1, changed considerably as compared to that for Condition 2.) Had data analysis kept pace with data collection, information to listeners concerning number of trials correct would have been discontinued and Ss would have been urged to respond according to how the stimuli "sounded"-a point referred to earlier.

The 10th listener was a high school female who had never before participated as a listener in any type of experiment and had never received any formal musical training. However, since early childhood she had been coached by her mother (also untrained) in singing and playing musical instruments; recently she had been singing professionally with her mother. For this listener, performance for Condition 2 did not differ from that of some other Ss (the DL was not smaller) but for Conditions 1 and 3 , essentially no change in slope of psychometric function or in PSE was produced by any interpolated tone. In a different experimental procedure, this $S$ displayed an extraordinary memory for pitch that deviated from performance of other Ss by several standard deviations. Either because of early training or because of genetically-determined characteristics, this listener apparently is "different" from the others. Although her responses cannot be disregarded (particularly when theoretic considerations are involved), they will not be further discussed in detail.

\section{CONCLUSIONS}

These data indicate that memory of a brief tone can be modified by a second tone occurring later. Greater interference occurs when the interpolated tone follows the target tone by a short period of time (i.e., $50 \mathrm{msec}$ ) than when it precedes the comparison tone. These data lend support to the hypothesis that frequency representation in the auditory system soon after stimulus onset is initially widespread and requires time to narrow or sharpen. Those frequencies that can interact with the target frequency in producing the described effects seem not restricted to the region of the critical band, but rather may extend over a very wide range.

The lack of univocality in the results for all listeners emphasizes the persistence of individual differences. A well documented study of temporal integration (Green, Birdsall, \& Tanner, 1957) measured rather different durations of energy integration for three different listeners. In analogous fashion, if the time required for development of auditory frequency contours by the 10th listener were much briefer than that required by average listeners, one would not expect performance in this experiment to be as much degraded by the interpolated tone.

These results differ from those of Postman who did not obtain time-order errors for pitch even when he inserted interpolated tones. Although Postman's experiment differed from this one along a number of dimensions, the two features of single target frequency (for a block of trials) and the relatively long target duration he used probably contributed most to his more stable pitch memory. In contrast, Wickelgren (1969, Fig. 10) has presented data that show a constant error, similar to that of the present experiment, when the target signal does not exceed $400 \mathrm{msec}$ and is followed by an interpolated tone. When the target signal in Wickelgren's experiment was longer, the constant error disappeared.

Thus, two conditions are required to produce constant error of pitch memory: brevity of the target tone and occurrence soon thereafter of an interpolated tone having a different frequency. Condition 2 of this experiment indicates that brevity of the target tone is not sufficient and Wickelgren's data, along with Postman's, indicate that an interpolated tone following a long target tone will not produce constant errors.

In summary, the statement that time errors or constant errors do not occur for pitch memory should be modified to include the qualification that the stimulus situation must permit the auditory system to develop and store veridical steady-state frequency contours. When this does not occur because the tonal signal is brief and because an interpolated tone of a different frequency occurs very soon thereafter, constant errors and $a$ marked decrease in the slope of the psychometric function may be observed.

\section{REFERENCES}

AIKEN, E. C., \& LAU, A. W. Memory for the pitch of a tone. Perception \& Psychophysics, 1966, 1, 231-233.

BACHEM, A. Time factors in relative and absolute pitch determination. Journal of the Acoustical Society of America, 1954, 26, 751.753 .

CROWDER, R. G., \& MORTON, J. Precategorical acoustic storage (PAS). Perception \& Psychophysics, 1969. 5, 365-373.

ELLIOTT, L. L. Development of auditory narrow-band frequency contours. Journal of the Acoustical Society of America. 1967, 42. 143-153.

ELLIOTT, L. L. Memory for the pitch of one and two tones. Paper read at Psychonomic Society meeting, October 1968.

GREEN, D. M.. BIRDSALL, T. G., \& TANNER, W. P. Signal detection as a function of signal intensity and duration. Journal of the Acoustical Society of America, 1957, 29, 523-531.

HARRIS. J. D. The decline of pitch discrimination with time. Journal of Experimental Psychology, 1952a, 43, 96-99.

HARRIS, J. D. Pitch discrimination. Journal of the Acoustical Society of A merica, 1952b, 24, $750-755$.

KOESTER, T., \& SCHOENFELD, W. N. The effect of context upon judgments of pitch differences. Journal of Experimental Psychology, 1946, 36, 417-430.

KOFFKA, K. Principles of Gestalt psychology. New York: Harcourt, Brace. 1935.

NEISSER, U. Cognitive psychology. New York: Appleton-Century-Crofts, 1967.

POSTMAN, L. The time-error in auditory perception. American Journal of Psychology, $1946,59,193-219$.

RIMM, D. C. The effect of interpolated stimulation on short-term memory for tones. Psychological Record. 1967, 17, 429-435.

SHOWER, E. G., \& BIDDULPH, R. Differential pitch sensitivity of the ear. Journal of the Acoustical Society of America, 1931, 2, 275-287.

TRESSELT, M. E. Time-errors in successive comparison of tonal pitch. American Journal of Psychology, 1948, 61. 335-342.

TURnbull, w. Pitch discrimination as a function of tonal duration. Journal of Experimental Psychology, 1944, 34, 302-316. WICKELGREN, W. A. Associative strength theory of recognition memory for pitch. Journal of Mathematical Psychology, 1969, 6. 13-61.

\section{NOTES}

1. Appreciation is expressed to Tracy Jackson who assisted with data collection and analysis. This research was supported in full by a U.S. Public Health Service. Department of Health, Education and Welfare research grant, NS03856. from the National Institute of Neurological Discases and Stroke.

2. Address: Central Institute for the Deaf. 818 South Euclid. St. Louis. Missouri 63110

3. Acknowledgment is, of course, also due to a tradition of experiments concerned directly with the classical question of time-error for pitch memory. These include studies by Postman (1946). Koester and Schoenfeld (1946), Tresselt (1948), Bachem (1954), Aiken and Lau (1966), and Rim (1967). Effects on judgments of tonal intensity ("loudness"), produced by time delays between target and comparison tones and by interpolated stimuli, are well known. Koffka (1935) has summarized and integrated relevant experiments by Lauenstein and Pratt.

4. Comparison of these data with those of another experiment. particular one conducted some years ago. may be questioned. Choicc of available comparisons is not wide. however, since studies have often not incorporated the range of frequencies required. If one uses data from an experiment by Harris (1952b), in which a roving standard procedure was not employed. the ratios of DI. at 8-sec delay (this study) to DL at $1.4 \mathrm{sec}$ become 4.0 at $250 \mathrm{~Hz}$ and 6.1 at $1.550 \mathrm{~Hz}$. The size of the ratios differs considerably from those reported in Table 2 but the same trend continues.

(Accepted for publication February 20, 1970.) 